\title{
Autism and Moral Responsibility: Executive Function, Reasons Responsiveness, and Reasons Blockage
}

\author{
Kenneth A. Richman
}

Received: 24 March 2017 / Accepted: 27 July 2017 /Published online: 12 August 2017

(C) The Author(s) 2017. This article is an open access publication

\begin{abstract}
As a neurodevelopmental condition that affects cognitive functioning, autism has been used as a test case for theories of moral responsibility. Most of the relevant literature focuses on autism's impact on theory of mind and empathy. Here I examine aspects of autism related to executive function. I apply an account of how we might fail to be reasons responsive to argue that autism can increase the frequency of excuses for transgressive behavior, but will rarely make anyone completely exempt from moral responsibility in general. On this account, although excuses may apply more often to autists than to others, the excuses that apply to autists are just the same excuses that can apply to anyone.
\end{abstract}

Keywords Autism · Responsibility - Executive function $\cdot$ Reasons responsiveness

Autism is characterized by differences in social interaction, differences in communication, and "restricted and repetitive interests and activities." [1] This triad manifests in such a multitude of ways that generalization is difficult, leading to the oft-repeated saying: "When you've met one

K. A. Richman $(\bowtie)$

School of Arts and Sciences, MCPHS University, 179 Longwood Avenue, Boston, MA 02115, USA

e-mail: kenneth.richman@mcphs.edu

K. A. Richman

Department of Philosophy, Linguistics, and Theory of Science, University of Gothenburg, Gothenburg, Sweden person with autism, you've met one person with autism." A variety of models have been promoted for explaining autism and shaping empirical research to further our understanding of autism spectrum condition. The most prominent of these models, though not the one we will emphasize here, portrays the key feature of autism as atypically low theory of mind (ToM) skills. ToM is what allows us to intuit the mental states of others, to understand that other thinkers have beliefs and expectations different from our own, etc.

Given the central role of the reactive attitudes in prominent accounts of responsibility [2], it is not surprising that autism should arise as a test case for accounts of who may and who may not rightly be held accountable. After all, autism affects the ability to understand and react to the expectations of others, and can lead to atypical reactions to what other people do. [3, 4] ToM abilities fit neatly into this exploration. Shoemaker [5] and Barnbaum [6], for example, focus their discussions of autism and responsibility on the way ToM challenges impact the ability of autistic agents (autists) to empathize with others. Kennett [7], and Krahn and Fenton [8] start with empathy more directly.

David Shoemaker argues that autism makes a person unable to engage in the moral enterprise: "...we might doubt that the relevant commitment of those with high-functioning autism is a moral

\footnotetext{
${ }^{1}$ This aphorism is attributed to Stephen Shore.
} 
concern. ... [because] their ends may be less about doing the right thing or taking others' interests as reason-giving and more about 'their need to abide by whatever rules they have been taught..." [5] Shoemaker ties this in with the claim that holding someone accountable involves demanding "acknowledgment and a certain emotional experience and transformation" that, on his description, is not possible for autists. [5] The result, on Shoemaker's view, is that autists should not be held morally responsible for their actions. Shoemaker's argument indicates a global exemption from responsibility, not just mitigated responsibility or excuses from responsibility for particular actions. ${ }^{2}$

Shoemaker's account seems to depend on a specific and limited account of autism as ToM impairment. Here, I look at autism understood as an executive function disorder. To apply a reasons responsiveness theory of responsibility to the case of autism understood as an executive function disorder, I describe several ways in which someone could fail to be reasons responsive. I argue that autism can increase the frequency of excuses for transgressive behavior, but will rarely make anyone completely exempt from moral responsibility in general. Furthermore, although excuses may apply more often to autists than to others, the excuses that apply to autists are just the same excuses that can apply to anyone.

In developing this position, I attempt to consider autism apart from other features or conditions that often accompany autism. We know that some autists are unable to engage socially or use language. General intellectual disability (low IQ) [9] and specific cognitive challenges such as working memory [10] can both contribute to this. When people are profoundly affected by these challenges, responsibility is not in question. There will, of course, be liminal cases, but the discussion that follows will apply to those who are able to engage socially, who appear generally to be among those it seems natural to blame or praise. These include, for example, the many people who come to organizations such as the National Autistic Society [11] in the UK and the Asperger/Autism Network (AANE) [12] in New England for social opportunities, support, and political action.

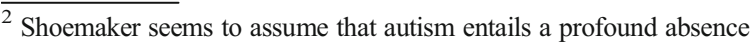
of certain abilities. Although there are people with such complete impairments, the data (some of which is discussed below) indicate that this is not how autism generally manifests.
}

\section{Autism and Executive Function}

Autism involves several areas of neuropsychological function. Researchers have emphasized various of these as one or the key driver of the differences seen in autists. Researchers have emphasized theory of mind [13], central coherence [14], executive function [15], empathy disorder $[16,17]$, extreme male brain [18], and other factors. [19, 20] Here we will focus on executive function. ${ }^{3}$

Executive function (EF) processes are "top-down" control mechanisms. They are "...mental processes needed when you have to concentrate and pay attention, when going on automatic or relying on instinct or intuition would be ill-advised, insufficient, or impossible..." [22] The core domains of EF are understood to be inhibitory control, working memory, and cognitive flexibility. [22] Inhibitory control involves behavioral inhibition, selective attention, and cognitive inhibition. Working memory includes "keeping active incoming information for further processing... the number of elements that can be held online simultaneously... [and] updating the content of working memory..." [23] Cognitive flexibility involves the ability to shift attention, and to adapt to changing environments or rules. [22] Higher order EFs such as "reasoning, problem solving, and planning" are "built" from the core domains. [22].

According to Robinson, et al., the theory that autism is, at its core, an EF disorder can account for the following typically atypical autistic tendencies: "a need for sameness, a strong liking for repetitive behaviours, lack of impulse control, difficulty initiating new non-routine actions and difficulty switching between tasks." [15] Robinson, et al. claim that these challenges "are not successfully accounted for by the theory of mind deficit hypothesis ... weak central coherence accounts ... or the extreme male brain theory." [15] Other groups have also put $\mathrm{EF}$ at the center of their explanations of challenges faced by autists. Ibrahim, et al. write that "Cognitive flexibility, planning, organization, and set shifting may represent vital processes that are necessary in expanding

\footnotetext{
${ }_{3}$ In "Reasons-Responsiveness and Moral Responsibility: The Case of Autism," Nathan Stout [21] discusses executive function challenges associated with autism to critique Fischer and Ravizza's widelydiscussed reasons responsiveness theory. Stout begins with the assertion that autism impairs accountability, and argues that, in at least some types of cases, Fischer and Ravizza's account gets this wrong. Here I start with a more neutral stance, and attempt to fill out the reasons responsiveness approach in a way that is useful for assessing the impact of autism understood as essentially a condition that affects executive functions.
} 
the repertoire of restricted, repetitive behaviours and meaningful social interactions." [24] Similarly, from Leung, et al.: "Deficits in inhibition, information recall, flexibility, and the ability to monitor, update, and select socially appropriate responses - all aspects of executive functioning - may contribute to the social impairments that characterize autism..." [3] Thus the executive function account is a reasonable way to understand autism. Furthermore, the fact that a number of researchers accept and employ this account shows the importance of exploring the implications for moral responsibility.

Neuropsychologists have a variety of instruments for assessing distinct and overlapping domains of executive function. [25] One instrument, the Wisconsin Card Sorting Test (WCST), asks subjects to sort cards into categories. The subject is expected to infer the active sorting rule (sort by shape type, shape color, or number of shapes) based on indication from the tester of whether the last sorting action was correct. The tester changes the rule at several points, requiring a new inference and a shift from following the old rule to following the new one. [26] The WCST engages a variety of EFs: "...success on the WCST requires that an individual be able to stop a current behavior, remember and keep active the rules and objectives of the task, and change strategies in order to sort by new, incompatible rules." [23].

In the Stroop Test, subjects are shown color words printed in an incongruous color. For instance, the word 'green' might appear in red ink. Subjects are asked to name the color of the ink. This is understood to test the subject's ability to inhibit the responses triggered by the meaning of the word in the prompt. [27].

Isolating which domains are affected by autism is tricky. [23] This becomes apparent in the literature on moral judgement. Data show that, compared to controls, autists tend to take less account of an agent's intentions when assigning blame to actions that cause harm. [28] Buon, et al. recognize two explanations for this. [28] One explanation cites ToM difficulties that impair autists' ability to take into account what the agent is thinking and the interpersonal norms being violated by the agent. The other explanation is that autists are less likely to inhibit the automatic, emotion-based response to the unintended harmful consequences of an action in favor of a judgement that reflects consideration of the agent's neutral intentions. This inhibition is expected under the "dual process model" of moral judgement. [29] Isolating the involvement of various EFs is further complicated by data suggesting that inhibition ability and ToM skills are actually correlated. [30].

Russo, et al., however, argue that "Among persons with autism, inhibition abilities appear to be intact..." [23] They draw this conclusion in part based on comparison between performance on the WCST, which shows higher errors in autistic subjects compared to appropriately matched controls, and performance on the Stroop Test which, though testing primarily inhibition, shows no difference attributable to autism for those above age six. Russo, et al. conclude that autists' lower performance on the WCST is due to lower function in updating short-term memory and in "set shifting/ cognitive flexibility," and is not attributable to lower inhibitory control. [23].

Data show subtle differences attributed to autism in the EF called verbal fluency (generativity), which falls in the category of cognitive flexibility. Verbal fluency requires subjects to generate words in a certain category (beginning with a certain letter, or naming members of a class such as animals). Contra Russo, et al., autists' comparatively high repetition of previously given answers seems to point toward inhibition difficulties. [15] In a study by Carmo, et al., [31] autists produced fewer words at the start of verbal fluency tasks compared to neurotypical controls, with production converging as the tests progressed. Carmo, et al. found that this difference was not present when an "initial word cue" was given, supporting their "impairment of initiation hypothesis" [31] about autism.

What can we make of this complicated scene? The familiar features of autism, such as focus on narrow interests, challenges with social interactions, insistence on sameness, and difficulty initiating new activities can be explained in terms of a few of the EFs described above. These are: shifting/cognitive flexibility, initiation, generativity and working memory. These EFs are important for considering counterfactual situations, identifying alternative paths, and adjusting to new information about people and circumstances.

In the next section, I describe the reasons responsiveness approach to moral responsibility. I will show that multiple aspects of reasons responsiveness are relevant 
to assessing the impact of executive function differences on moral responsibility in autists.

\section{Responsibility and Reasons Responsiveness}

I am interested here in moral responsibility as accountability. Theories of accountability tell us when it is appropriate to hold a person to account - to blame someone, e.g.- for an action. Although some philosophers are skeptical about attributing moral responsibility at all, [32, 33] I take it as given that typical adults do things for which they are morally accountable, and also do things for which they are not morally accountable. I might deserve blame for carelessly causing a forest fire; I might be blameless for stepping on an endangered snail that I did not see on the sidewalk.

As with autism, moral responsibility has been subject to multiple theoretical accounts. [34] Here I will focus on a family of theories that dominates current philosophical treatments of the topic: reasons responsiveness theories. Roughly, reasons responsiveness accounts tell us that an agent is responsible for an action if she has the capacity to alter her behavior in the face of relevant reasons to do so. As with the executive function theory of autism, the reasons responsiveness approach to responsibility is widely discussed and defended [5, 21, 32, 35], seems reasonable, and helps to explain the relevant phenomona. These are reasons to take seriously the implications of the reasons responsiveness approach for autism.

Fischer and Ravizza give a canonical reasons responsiveness account. According to Fischer and Ravizza, moral responsibility requires reasons receptivity and reasons reactivity. These are explained in terms of "mechanisms" in an agent:

In the case of receptivity to reasons, the agent (holding fixed the relevant mechanism) must exhibit an understandable pattern of reasons-recognition, in order to render it plausible that his mechanism has the "cognitive power" to recognize the actual incentive to do otherwise. In the case of reactivity to reasons, the agent (when acting from the relevant mechanism) must simply display some reactivity, in order to render it plausible that his mechanism has the "executive power" to react to the actual incentive to do otherwise. [35]
Being a responsible agent, on this theory, requires that one have access to the reasons that are relevant to choices about how to act, and the ability to adjust action in response to those reasons. We cannot set as the standard for being a responsible agent that a person always responds to relevant reasons, as that would mean that anyone who acts wrongly in any instance would fail to be a responsible agent, eliminating the possibility of culpable wrongdoing. This is why Brink and Nelkin note that "...responsibility must be predicated on the possession, rather than the use, of such capacities. We do excuse for lack of competence. We do not excuse for failures to exercise these capacities properly." [36].

For Fischer and Ravizza, moral responsibility is inseparable from experience of appropriate moral sentiments or, in the case of a detached consideration, the recognition that such sentiments would be appropriate in the circumstance. [35] When we feel moral sentiments, we are feeling the moral character of reasons for acting (or at least for making moral judgments). The moral sentiments include reactive emotions that give us a sense of the moral significance of a fact. Importantly, this encompasses what Strawson and followers call the reactive attitudes. [2, 37] The reactive attitudes (resentment or gratitude, e.g.) are, on many views, integral or even constitutive of holding someone responsible. [2].

We could have a reasons responsiveness theory that did not involve moral feelings at all. For some, however, such a theory would not be a theory of moral responsibility. [2, 5] On these theories, responses to reasons are moral (rather than merely prudential) only if they involve moral feelings.

Fischer and Ravizza are not, of course, the only philosophers to have developed a reasons responsiveness account that presents feelings as central to the character of moral engagement. Shoemaker leans heavily (as he puts it) on anger and gratitude as the "fitting" sentiments for holding a person accountable. [5] Wallace describes responsibility in terms of "a distinctive kind of normative competence: the general capacity to grasp moral reasons, and to guide one's conduct by the light of such moral understanding" [38], where this moral understanding is "distinctively connected to the reactive emotions." [38] McKenna admits that reactive emotions "might well only be contingently related to our moral responsibility practices," yet treats them as "bedrock ingredients in an accurate and informative characterization of what moral responsibility is." [39]. 
The role of moral feelings in reasons responsiveness accounts is, as already suggested, to mark the moral valence of an action. The idea captured in these accounts is that a person who does not generate reactive emotions when contemplating relevant reasons does not have access (is not receptive) to moral facts, and therefore cannot be held morally responsible.

These accounts cannot allow that just any response will capture the moral scene accurately. Reactive emotions must be: "fitting" [40], justified and "aimed at a sensible target" [41]; natural and universal [42]; "natural or reasonable or appropriate..." [2] Fittingness is how these theories distinguish between correct and incorrect judgments. Atypical responses will not count as fitting. Stout's suggested revision of Fischer and Ravizza's reasons responsiveness requirement calls for systems that are "functionally typical" [21], which indicates the connection between these ideas and concepts of health. ${ }^{4}$

Brink and Nelkin's account of "the architecture of responsibility" describes reasons responsiveness in terms of what they call "normative competence." Normative competence "...requires responsible agents to be able to recognize and respond to reasons for action." [36] 'Recognize' refers to what Fischer and Ravizza call receptivity to reasons, and is the basis of "the cognitive dimension of normative competence." [36] 'Respond' refers to what Fischer and Ravizza call reasons reactivity, and is the basis of "the volitional dimension of normative competence." [36].

Someone without normative competence is not morally responsible for her actions. But how might we fail to have normative competence? On the cognitive side, Brink and Nelkin start with the ability to "recognize wrongdoing." [36] On Shoemaker's theory of accountability, the key is the capacity to have regard for others, where my regard for you involves considering your projects to be meaningful and valuable because you find them so. [5].

However, failure of normative competence in its cognitive component (failure to recognize wrongdoing, failure of regard, failure of reasons receptivity) seems to be possible in multiple ways. So, too, does failure of normative competence in its volitional component (failure of reasons reactivity). What we know about autism

\footnotetext{
${ }^{4}$ Health is certainly relevant when thinking about neurodevelopmental conditions, but we must be wary not to revert to old ideas connecting illness or being atypical with vice.
}

can help tease these out in a way that may, perhaps, be useful for understanding both reasons responsiveness and the ways in which autism can impact normative competence. In the next section, I describe several ways in which a person could fail to be reasons responsive. I understand these to be compatible with a wide variety of reasons responsiveness theories.

\section{Reasons Responsiveness in Detail}

Agent A could fail to respond to reasons in a particular case in several ways. It is possible to fail in some of these ways and be blameworthy for this failure. For instance, A could fail to perceive a relevant, available fact $\mathrm{F}^{5}$ because she was not paying attention when she should have been. ${ }^{6}$ Alternatively, A could have been unable to receive or attend to $F$ due to a non-culpable failure of her reasons responsiveness mechanisms. This failure could be global and permanent. Alternatively, it could be limited in time and/or scope. Nonculpable failure to be reasons responsive that is merely situational or partial would be an excuse for relevant actions or omissions. Non-culpable failure to be reasons responsive that is pervasive and regular would make for global exemption from responsibility.

Consider the following five types of failure:

1. A does not perceive relevant, available fact $\mathrm{F}$.

2. A perceives $\mathrm{F}$, but does not perceive $\mathrm{F}$ as a moral reason.

3. A perceives $\mathrm{F}$ as a moral reason but does not find this motivating (can't be bothered).

4. A is motivated in a general sense but fails to conform her will to respond.

5. A can conform her will generally, but is unable to select an appropriate response.

My primary concern here is to consider when A would be not accountable. Therefore, in what follows I will focus on non-culpable failures to be reasons responsive.

\footnotetext{
${ }^{5}$ Here I will use 'perceive' in the very general sense of having some content before the mind.

${ }^{6}$ In Björnsson and Brülde's terms, this would be a failure to satisfy a duty to care. [43]
} 
Failures of types 1, 2, and 5 are failures of cognitive competence. ${ }^{7}$ Leaving aside cases where a reason is not in any sense available to agents (for instance, because the only evidence is behind a locked door), type 1 failures might include not noticing that a friend is sad or not recognizing a serious threat to a child's safety. Where a typical observer or participant in the scene would have picked up on these facts, someone else might in a sense be blocked from them. Here A would fail to be reasons receptive because she experiences a sort of reasons blockage.

But perceiving a fact is not the same as recognizing it as a moral reason to act. In one kind of type 2 failure, A might perceive $\mathrm{F}$ but not as a reason to act at all. In a second case, A might perceive $\mathrm{F}$ as a reason to act, but not as a moral reason for action. For instance, A might perceive a safety hazard, know that it would be inconvenient if her son were injured, and act for that reason rather than on the moral ground that she has an obligation to protect her child. These are the failures of reasons responsiveness attributed to the hypothetical psychopath. ${ }^{8}$ The psychopath may be clever and observant. She might recognize the relevant facts and know how to manipulate the world, [5] but she lacks a moral sense that reacts to some facts as moral reasons. [5, 44, 46] This kind of type 2 failure is lack of reasons receptivity. The psychopath is reasons blocked because of failure to apprehend the moral relevance of $\mathrm{F}$.

In a third sub-type of failure 2, A might perceive $\mathrm{F}$ as morally relevant, but fail to perceive $\mathrm{F}$ as a moral reason for action due to failure to recognize the availability of possible responses. The fact that someone is suffering is not a reason to act if I am actually powerless to do anything about it. If I mistakenly believe I am powerless to address suffering because of an inability to identify responses that are in fact available, that would also be a type 2 case of failing to be reasons receptive. In this type of failure, A perceives $\mathrm{F}$, and perceives the moral salience of $\mathrm{F}$, but this does not trigger action because $\mathrm{A}$ is blocked to

\footnotetext{
${ }^{7} 5$ could be understood to overlap with volitional competence under Brink and Nelkin's description. [36]

${ }^{8}$ I will use the term 'psychopath' here to refer to the character referred to in this way in the philosophical literature. [7, 44-46] I will not be concerned for whether this represents any clinically accurate account of any actual person.
}

possible responses. This is different from the psychopath's type 2 failure in that (assuming a nonpsychopath A) A would have perceived $\mathrm{F}$ as moral reason for acting had she been able to identify the alternative actions that were available. ${ }^{9}$

It may also be possible to recognize and react to relevant reasons, but choose poorly because of prioritizing wrongly among relevant reasons. This would be a fourth subtype of type 2 failures. For instance, A might have time to run quickly into a burning house just once before it becomes too unsafe to do so. Suppose A uses this opportunity to save her comic book collection (the subject of her special, intense interest) rather than to check that all of her family members are safely out of the house. Suppose also that A was aware that checking for other people was a possible and morally relevant alternative action, that prioritizing the comic book collection over checking for family members was the wrong choice, and that this is not an instance of akrasia. On a reasons responsiveness account, assessment of culpability for this action depends on whether A's reasons receptiveness mechanisms were working properly. If so, A could be blameworthy for her choice. On the other hand, the intense, "restricted and repetitive interests and activities" [1] associated with autism, and the associated challenges with inhibition may interfere with A's ability to "exhibit an understandable pattern of reasons-recognition" [35], so that she would not be blameworthy. In this case, A would be blocked from seeing the primacy of the morally right choice.

Type 5 failures are different from type 2 in that, in type 5 , A has recognized $\mathrm{F}$ as a morally relevant reason to act and A's motivation is aligned, but action is not forthcoming due to difficulty choosing an appropriate response. This would be a limitation in A's practical reason-phronesis. She has a goal (to act in response

\footnotetext{
${ }^{9}$ Kalis and Meynen identify three stages of decision-making: option generation, option selection, and action initiation. They argue that “... assessing option-generation dysfunctions is highly relevant for judgments of moral and criminal responsibility." [47] "Various mental disorders decrease a patient's capability to see those options for action that most people can easily see, or they lead one to see options for action that most people would not see as options." [47] They use psychosis, schizophrenia, depression, compulsive disorders such as pyromania, and ADHD as examples.

Kalis and Meynen argue that option generation is most relevant because we have the least control over it, and because option generation frames the possibilities for option selection and action initiation. As a result, they claim, those whose option generation is impaired should not be held responsible for poor option selection or action initiation.
} 
to a moral reason) and the will to pursue that goal. She is able to martial the volitional forces, but has, as Grisso and Appelbaum put it, "difficulty in the processing of information to make a decision." [48] This would not be reasons blockage, or A would not have perceived $\mathrm{F}$ as a moral reason for action. However, challenged cognitive flexibility might interfere with A's ability to compare the consequences of competing potential actions. Initiation (getting going, as described by Carmo, et al. [31]) could also be a factor.

3 and 4 would be failures of volitional competence. It is not clear, however, whether failure 3 is possible. On one reading, recognizing $\mathrm{F}$ as a moral reason involves feeling a moral reactive emotion, and moral reactive emotions are inherently motivating. On this view, it is not possible for $\mathrm{A}$ to perceive $\mathrm{F}$ as a moral reason and fail to be motivated by this to act in some way, because being motivated just is what it means to perceive a fact as a moral reason. I do not think a lot rides on whether 3 is possible. 4 is a more familiar sort of failure, involving an experience of being motivated to act but doing something else instead, something that is not endorsed by a second-order desire. That would be akrasia.

\section{Autism, Executive Function, and Failure of Reasons Responsiveness}

We can see how EF challenges in the area of generativity could contribute to non-culpable failures of type 2. Someone might fail to be reasons responsive because she is blocked from the fact that she has options available for responding to a relevant fact. This could cause her not to perceive the fact as a moral reason to act (a type 2 failure). Cognitive flexibility challenges could lead to non-culpable failures of type 5 .

Type 1 failures could possibly connect to EF in cases where A fails to notice $\mathrm{F}$ due to slowness in updating working memory. For instance, A might not adjust her behavior to a new facial expression indicating that her friend has become sad or frightened. However, we know that autism is also characterized by a general tendency to miss social cues that trigger reactive emotions in neurotypicals. These might better be explained by ToM challenges, and by relatively low orientation to social circumstances.

Anecdotal evidence suggests that the type 2 failures expected of the psychopath are rare for autists. An autist who perceives relevant facts (her friend is crying) may have less access to the emotion her friend is feeling, may feel that emotion through emotional contagion without realizing that it originates with the friend [49], or may not identify the possible responses that are available, but this is not the same as the psychopath's indifference to the friend's sadness. ${ }^{10}$

So it looks like the executive function challenges characteristic of autism can affect a person's reasons responsive mechanisms. Reasons receptivity/cognitive competence and reasons reactivity/volitional competence were not specific enough categories to allow us to assess the impact of autism-related EFs on reasons responsiveness. Breaking down reasons responsiveness failures into types $1-5$, with further distinctions within type 2, gives us more information about reasons responsiveness, and provides a framework for improved understanding of autism.

Autism can cause reduced reasons responsiveness, typically involving some form of reasons blockage. Reasons blockage affects reasons receptivity (cognitive competence). Although there will be some autists whose impairments are profound, it is likely that few autists who are otherwise able to engage socially will be globally exempt from moral responsibility due to lack of reasons responsiveness. Reduced reasons responsiveness is more likely to ground excuses in particular situations. Again, reduced reasons responsiveness should not be confused with culpable failure to engage one's reasons responsive capacities.

The particular excuses identified here as caused by autism will be the same types of excuse that sometimes apply to neurotypicals. Neurotypicals can simply not register facts or fail to perceive options even when they are paying appropriate attention. These phenomena can sometimes be excuses even for those who are quite reliably reasons responsive. Indeed, we know that executive functions are impacted in any person who is tired, stressed, or even lonely. [22] This means that autists are not different in kind from neurotypical people, just subject to more of the common sorts of moral frailties. Autists may also be less able to avoid these frailties through ordinary means (such as getting sufficient sleep).

Knowing that a person is autistic would be a reason to look for particular types of excuses, and to accept these excuses more often than we would for those who

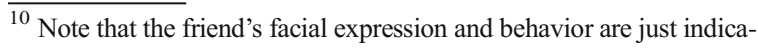
tors of the morally relevant fact, which is that the friend is sad.
} 
are not autistic. Diversity among the neurodiverse makes it especially challenging to identify whether and how often a particular individual should be excused. Variation in degree of difference on various measures, the particulars of actual circumstances, and co-existing conditions such as alexithymia and intellectual disability are all relevant factors.

Some adults on the autism spectrum have suggested approaching this on the model used in education. ${ }^{11}$ All students can benefit from individualized instruction, but state-funded schools are expected to provide individualized educational plans (IEPs) to students who have atypical neuropsychology profiles. IEPs are generated on the basis of extensive assessment, and in consultation with teachers, parents, clinicians, and, where appropriate, the student. It might also make sense to construct an "individualized responsibility plan" (IRP). Because of the resources needed, an IRP would most likely be written in response to a specific incident or legal charge. However, it would be generalizable, and could be used as a guide to help an autistic adult avoid potentially problematic situations in the future, such as might arise in school or the workplace.

It is also worth considering that differences characteristic of autism might enhance the ability to be responsible in some circumstances. This could be parallel to how monotropism (narrow focus of interest [50]) is understood as an advantage in certain careers, such as computer programming or database management. [51].

\section{Respect and the Responsibility to Engage in the Moral Community}

Participating in the moral community is not just another activity. I might be poor at playing darts or folding origami, and may be frustrated by this. However, these activities are not good in themselves. I can find other meaningful activities without missing out on anything profound. However, there is a duty of moral engagement, to live life as a moral agent when possible. Failing to step up in this way, or otherwise opting out of moral engagement means failing to treat people (perhaps including oneself) as ends in themselves.

Fulfilling the duty to realize one's potential for moral engagement will be harder for autists given the

\footnotetext{
${ }^{11}$ Here I am indebted to contributions from Holly Judge, Elizabeth Wady, and Paul Wady.
}

challenges identified above. Although this is a reason to excuse autists for falling short, there still appears to be a duty to try even though trying will generally take more effort for autists than for neurotypicals. This may seem troubling. Human diversity may contribute to different levels of success on a variety of measures, but autism should not make it harder for someone to be a good person.

Three responses to this worry are available. We might see this as a reason to re-visit the concept of moral responsibility and look for an account of responsibility under which autists can be fully responsible without needing to work too much harder than others. Kennett takes an approach like this. [7] We might bite the bullet, though it may seem unjust, and say that autists are obligated to work harder than neurotypicals at moral engagement because it is a duty to do so. Alternatively, we might hold that autism simply reduces the obligation for moral engagement in some way. The first response is outside the scope of this paper, which is intended to draw out the implications of combining reasons responsiveness as an approach to moral responsibility with an understanding of autism as driven primarily by EF challenges. The second and third responses capture the horns of a significant dilemma, or at least two opposing forces that need to be balanced.

Although excusing someone for a transgression can be a kind, empathetic response that recognizes the individual's vulnerability, it can also have a flavor of infantilizing parentalism. ${ }^{12}$ Holding someone accountable is part of treating that person as an adult, as a full member of the moral community. There is every reason to believe that autistic adults want to be held accountable, and also want to be excused when autism has made them reason blocked. ${ }^{13}$ This suggests, quite reasonably, that the default approach should be to treat adult autists as accountable, with adjustments for particular circumstances. Of course, this will not apply to those with profound impairments that keep them from engaging in social interactions generally.

Nelkin has argued that "difficulty is a factor in determining degrees of blameworthiness and praiseworthiness." [53] If we accept this, we can say that autism can be a factor that reduces the scope and

\footnotetext{
${ }^{12}$ This is in broad import the same tension as the rescue/blame conundrum discussed by Hanna Pickard in her discussions of responsibility without blame. [52]

${ }^{13}$ Here again I draw on my understanding of contributions from Holly Judge, Elizabeth Wady, and Paul Wady.
} 
degree of moral responsibility in some individuals. When autism causes non-culpable failure of reasons responsiveness as outlined above, this will put an action outside the scope of moral responsibility for the affected person. Where autism does not cause failure of reasons responsiveness, but does make it atypically difficult to employ an individual's reasons responsive mechanisms, this can reduce the degree of blameworthiness should this person fail to respond to reasons in the particular circumstance.

When we are responsible for an action, we have an obligation to take responsibility for it. On a practical level, there might also be situations in which it makes sense for someone to take responsibility even when she was not strictly speaking responsible. (Cf Enoch [54]) This could be important to help an offended party make sense of the circumstance. It might be an opportunity to practice behaviors and reinforce habits of attention to promote an agent's ability to be responsible when similar circumstances arise in the future. (Cf Pickard [52]) We might also want to take responsibility in order to maintain trust (within ourselves or others) in our agency.

\section{Conclusion}

Determinations of whether and how autism might be a reason to excuse or even exempt someone from being morally accountable for behavior appear to hinge on how we choose among models of autism and among approaches to responsibility. The current paper looked at this question using an executive function model of autism and a reasons responsiveness approach to moral responsibility. We saw that executive function challenges may cause partial reasons blockage. Reasons blockage is not a failure of reactive attitudes or moral sensibilities. Like visual or hearing impairments, reasons blockage can keep some relevant facts from being available to some agent $\mathrm{A}$. Reacting to those facts cannot therefore be "properly morally demanded of" A. [55].

Unlike Shoemaker, who argues in Responsibility from the Margins that autists are exempt from accountability [5], I concluded that autism will in most cases just increase the frequency of the types of excuses that sometimes apply to neurotypicals. This is because autism challenges executive function, but does not eliminate executive function. This understanding of how autism impacts moral responsibility provides a context for addressing the challenge of balancing respectful blame and compassionate exculpation.

Acknowledgements This work was supported by the Miriam Foundation of Montreal Additional support was provided by the Gothenburg Responsibility Project, and a sabbatical award from MCPHS University. I am indebted to Abe Fuchs, and to members of the Gothenburg Responsibility Project - particularly Per-Erik Milam, Sofia Jeppsson, and Benjamin Matheson-for helpful responses to earlier versions of this paper.

\section{Compliance with Ethical Standards}

Informed Consent This article refers to individuals who shared their ideas as expert consultants. Although the MCPHS University Institutional Review Board determined that this did not constitute research involving human subjects, informed consent was obtained from all individuals for whom identifying information is included in this article.

Open Access This article is distributed under the terms of the Creative Commons Attribution 4.0 International License (http:// creativecommons.org/licenses/by/4.0/), which permits unrestricted use, distribution, and reproduction in any medium, provided you give appropriate credit to the original author(s) and the source, provide a link to the Creative Commons license, and indicate if changes were made.

\section{References}

1. Happé, Francesca, Angelica Ronald, and Robert Plomin. 2006. Time to give up on a single explanation for autism. Nature Neuroscience 9: 1218-1220.

2. Strawson, Peter F. 1974. Freedom and resentment. In Freedom and Resentment and Other Essays, 1-25. London: Methuen.

3. Leung, Rachel C., Vanessa M. Vogan, Tamara L. Powell, Evdokia Anagnostou, and Margot J. Taylor. 2016. The role of executive functions in social impairment in autism spectrum disorder. Child Neuropsychology 22: 336-344.

4. Baron-Cohen, Simon. 1995. Mindblindness: An essay on autism and theory of mind. Cambridge: MIT Press.

5. Shoemaker, David. 2015. Responsibility from the margins. New York: Oxford University Press.

6. Barnbaum, Deborah R. 2008. The ethics of autism: Among them, but not of them. Bloomington: Indiana University Press.

7. Kennett, Jeanette. 2002. Autism, empathy and moral agency. The Philosophical Quarterly 52: 340-357.

8. Krahn, Timothy, and Andrew Fenton. 2009. Autism, empathy and questions of moral agency. Journal for the Theory of Social Behaviour 39: 145-166.

9. Schatz, Jeffrey, and Ghada Hamdan-Allen. 1995. Effects of age and IQ on adaptive behavior domains for children with autism. Journal of Autism and Developmental Disorders 25: 51-60. 
10. Schuh, Jillian M., and Inge-Marie Eigsti. 2012. Working memory, language skills, and autism symptomatology. Behavioral Science 2: 207-218.

11. The National Autistic Society. 2017. http://www.autism.org. uk/. Accessed 13 June 2017.

12. Asperger/Autism Network (AANE). 2017. http://www.aane. org/. Accessed 13 June 2017.

13. Baron-Cohen, Simon, Allen M. Leslie, and Uta Frith. 1985. Does the autistic child have a "theory of mind"? Cognition 21: 37-46.

14. Happé, Francesca, and Uta Frith. 2006. The weak coherence account: Detail-focused cognitive style in autism spectrum disorders. Journal of Autism Developmental Disorders 36: 5-25.

15. Robinson, Sally, Lorna Goddard, Barbara Dritschel, Mary Wisley, and Patricia Howlin. 2009. Executive functions in children with autism spectrum disorders. Brain and Cognition 71: 362-368.

16. Smith, Adam. 2009. The empathy imbalance hypothesis of autism: A theoretical approach to cognitive and emotional empathy in autistic development. The Psychological Record 59: 9.

17. Gillberg, Christopher L. 1992. The Emanuel Miller Memorial Lecture 1991. Autism and autistic-like conditions: Subclasses among disorders of empathy. Journal of Child Psychology and Psychiatry 33: 813-842.

18. Baron-Cohen, Simon. 2002. The extreme male brain theory of autism. Trends in Cognitive Sciences 6: 248-254.

19. Lawson, John. 2003. Depth accessibility difficulties: An alternative conceptualisation of autism spectrum conditions. Journal for the Theory of Social Behaviour 33: 189-202.

20. Vermeulen, Peter. 2015. Context blindness in autism spectrum disorder. Focus on Autism and Other Developmental Disabilities 30: 182-192.

21. Stout, Nathan. 2016. Reasons-responsiveness and moral responsibility: The case of autism. The Journal of Ethics 20: 401-418.

22. Diamond, Adele. 2013. Executive functions. Annual Review of Psychology 64: 135-168.

23. Russo, Natalie, Tara Flanagan, Grace Iarocci, Darlene Berringer, Philip David Zelazo, and Jacob A. Burack. 2007. Deconstructing executive deficits among persons with autism: Implications for cognitive neuroscience. Brain and Cognition 65: 77-86.

24. Ibrahim, George M., Benjamin R. Morgan, Vanessa M. Vogan, Rachel C. Leung, Evdokia Anagnostou, and Margot J. Taylor. 2016. Mapping the network of neuropsychological impairment in children with autism spectrum disorder: A graph theoretical analysis. Journal of Autism and Developmental Disorders 46: 3770-3777.

25. Chan, Raymond C.K., David Shum, Timothea Toulopoulou, and Eric Y.H. Chen. 2008. Assessment of executive functions: Review of instruments and identification of critical issues. Archives of Clinical Neuropsychology 23: 201-216.

26. Stoet, Gijsbert. 2016. PsyToolkit. http://www.psytoolkit. org/experiment-library/wcst.html. Accessed 17 February 2017.

27. Scarpina, Federica, and Sofia Tagini. 2017. The Stroop color and word test. Frontiers in Psychology 8: 557.

28. Buon, Marine, Emmanuel Dupoux, Pierre Jacob, Pauline Chaste, Marion Leboyer, and Tiziana Zalla. 2013. The role of causal and intentional judgments in moral reasoning in individuals with high functioning autism. Journal of Autism and Developmental Disorders 43: 458-470.

29. Buon, Marine, Ana Seara-Cardoso, and Essi Viding. 2016. Why (and how) should we study the interplay between emotional arousal, theory of mind, and inhibitory control to understand moral cognition? Psychonomic Bulletin and Review 23: 1660-1680.

30. Carlson, Stephanie M., Louis J. Moses, and Laura J. Claxton. 2004. Individual differences in executive functioning and theory of mind: An investigation of inhibitory control and planning ability. Journal of Experimental Child Psychology 87: 299-319.

31. Carmo, Joana C., Elsa Duarte, Cristiana Souza, Sandra Pinho, and Carlos N. Filipe. 2017. Brief report: Testing the impairment of initiation processes hypothesis in autism spectrum disorder. Journal of Autism and Developmental Disorders: 1-5.

32. Pereboom, Derk. 2007. Hard Incompatibilism. In Four Views on Free Will, ed. John Martin Fischer, 85-125. Oxford: Blackwell.

33. Strawson, Galen. 2011. Freedom and belief. Oxford: Oxford University Press.

34. Eshleman, Andrew. 2016. Moral responsibility. In The Stanford Encyclopedia of Philosophy, winter 2016 ed., ed. Edward N. Zalta. Palo Alto: Metaphysics Research Lab, Stanford University.

35. Fischer, John Martin, and Mark Ravizza. 1998. Responsibility and control: A theory of moral responsibility. Cambridge: Cambridge University Press.

36. Brink, David O., and Dana K. Nelkin. 2013. Fairness and the architecture of responsibility. In Oxford Studies in Agency and Responsibility, volume 1, ed. David Shoemaker, 284 313. Oxford: Oxford University Press.

37. McKenna, Michael, Paul Russell, eds. 2016. Free will and reactive attitudes: Perspectives on P.F. Strawson's "freedom and resentment". Oxford: Routledge.

38. Wallace, R.J. 2002. Précis of Responsibility and the Moral Sentiments. Philosophy and Phenomenological Research 64: 680-681.

39. McKenna, Michael. 2012. Conversation and responsibility. Oxford: Oxford University Press.

40. Wallace, R.J. 2008. Emotions, expectations and responsibility. In Free will and reactive attitudes: Perspectives on P.F. Strawson's "freedom and resentment", ed. Michael McKenna and Paul Russell, 157-185. Farnham, England: Ashgate.

41. Fischer, John Martin, and Neal A. Tognazzini. 2011. The physiognomy of responsibility. Philosophy and Phenomenological Research 82: 381-417.

42. Hume, David. 1975. Enquiries concerning human understanding and concerning the principles of morals. Oxford: Clarendon Press.

43. Björnsson, Gunnar, and Bengt Brülde. 2017. Normative responsibilities: Structure and sources. In: Parental Responsibility in the Context of Neuroscience and Genetics, ed. Kristien Hens, Daniela Cutas, and Dorothee Horstkötter, 13-33. Dordrecht: Springer.

44. Levy, Neil. 2007. The responsibility of the psychopath revisited. Philosophy, Psychiatry, and Psychology 14: 129-138. 
45. Glannon, Walter. 2008. Moral responsibility and the psychopath. Neuroethics 1: 158-166.

46. Elliott, Carl. 1992. Diagnosing blame: Responsibility and the psychopath. The Journal of Medicine and Philosophy 17: 199-214.

47. Kalis, Annemarie, and Gerben Meynen. 2014. Mental disorder and legal responsibility: The relevance of stages of decision making. International Journal of Law and Psychiatry 37: 601-608.

48. Grisso, Thomas, and Paul S. Appelbaum. 1998. Assessing comp etence to consent to treatment: A guide for physicians and other health professionals. New York: Oxford University Press.

49. Bird, Geoffrey, and Essi Viding. 2014. The self to other model of empathy: Providing a new framework for understanding empathy impairments in psychopathy, autism, and alexithymia. Neuroscience and Biobehavioral Reviews 47: 520-532.
50. Murray, Dinah, Mike Lesser, and Wendy Lawson. 2005. Attention, monotropism and the diagnostic criteria for autism. Autism 9: 139-156.

51. Hickey, Shane. 2015. The innovators: Matching autistic people with jobs needing special skills. The Guardian. (19 April).

52. Pickard, Hanna. 2011. Responsibility without blame: Empathy and the effective treatment of personality disorder. Philosophy, Psychiatry, and Psychology 18: 209-223.

53. Nelkin, Dana K. 2016. Difficulty and degrees of moral praiseworthiness and blameworthiness. Nous 50: 356-378.

54. Enoch, David. 2012. Being responsible, taking responsibility, and penumbral agency. Oxford: Oxford University Press.

55. Björnsson, Gunnar. (Forthcoming) Explaining (away) the epistemic condition on moral responsibility. In Responsibility-The Epistemic Condition, ed. Philip Robichaud, and Jan Willem Wiel. Oxford: Oxford University Press. 